\title{
Vagus Nerve Stimulation could also Alleviate Respiratory Infections as Part of its Anti-inflammatory Property
}

\author{
Satish Dipankar
}

\section{Satish Dipankar}

Department of Physiology, AlIMS, Patna, INDIA.

\section{*Correspondence}

\section{Dr. Satish Dipankar}

Associate Professor, Department of Physiology, All India Institute of Medical Sciences, Patna-801507, Bihar, INDIA.

Phone: +91 9923030375

Email: dipankarsp@gmail.com

History

- Submission Date: 18-04-2020;

- Review completed: 22-05-2020;

- Accepted Date: 15-06-2020.

DOI : 10.5530/ijcep.2020.7.2.21

Article Available online http://www.ijcep.org

\section{Copyright}

(c) 2020 Phcog.Net. This is an openaccess article distributed under the terms of the Creative Commons Attribution 4.0 International license.
Dear Sir,

I read very attentively your recent Editorial on the "Vagus Nerve: The Key Integrator of Anti-inflammatory reflex" published in IJCEP 2020;7(1):1-2 and I found it to be a very useful article with insights deep into the anti-inflammatory role of vagus nerve. Thank you for enlightening us on the topic. I am happy to share my observation on the topic.

The vagus nerve is the longest nerve of the body that innervates thoracic and many visceral organs. The role of the vagus nerve in anti-inflammatory reflex has opened the opportunity for the scientists to study ANS mediated anti-inflammatory responses. Apart from the immediate significance of the term anti-inflammatory reflex, the biological and clinical consequences of this immune system hyperactivity are by far less known, making it worthwhile to be overviewed. I would like to add further that excessive uncontrolled inflammatory response results in cytokine storms syndrome which is nothing but fatal hyper-cytokinemia associated with multiorgan failure. This response is observed recently in pneumonia /ARDS in the severe COVID-19 positive cases. Other like viruses of $\mathrm{n}$-corona stimulating cytokine storm syndrome mimic the components of the chemokine system by producing molecules that are very similar to chemokines and can interact

with their receptor. Some chemokines play a direct anti-viral effect by inducing an array of phenomena that lead cells to determine an "anti-viral state". These phenomena include activation of apoptosis or direct killing of infected cells by activated immune cells. Few studies demonstrated that chemokine CXCL10 levels, as evaluated in serum, bronchial-alveolar washing fluid, or nasal secretions, consistently correlate with the severity and duration of acute respiratory tract infection due to viral infections.

Your editorial focused very well on the vagus nerve and its role on the neuro-immune axis in the regulation of inflammatory responses. The vagus nerve a mixed nerve with $4 / 5$ afferent and $1 / 5$ efferent fibers, is a key component of the neuro-immune and braingut axes through bidirectional communication between the brain and the gastrointestinal tract. A dual anti-inflammatory role of the vagus nerve is observed using either vagal afferents, targeting the hypothalamic-pituitary-adrenal axis, or vagal efferent, targeting the cholinergic anti-inflammatory pathway. Of course, an increase in vagal tone through yogic exercises is linked to a reduction in inflammation and better prognosis in people suffering from chronic illness, anxiety, or depression. Vagal tone is measured in the changes in heart rate that occur with the breath which we refer to as Heart Rate Variability (HRV).

Cite this article: Dipankar S. Vagus Nerve Stimulation could also Alleviate Respiratory Infections as Part of its Anti-inflammatory Property. Int J Clin Exp Physiol. 2020;7(2):87. 